\title{
Molecular detection of Toxoplasma gondii DNA in milk and risk factors analysis of seroprevalence in pregnant women at Sharkia, Egypt
}

\author{
Heba A. Ahmed ${ }^{1}$, Saleh M. Shafik ${ }^{2}$, Mahmoud E. M. Ali ${ }^{2}$, Sanya T. Elghamry ${ }^{2}$ and Alshymaa A. Ahmed ${ }^{3}$ \\ 1. Department of Zoonoses, Faculty of Veterinary Medicine, Zagazig University, 44511, Zagazig, Egypt; \\ 2. Food Hygiene Department, Animal Health Research Institute, Mansoura, Egypt; \\ 3. Clinical pathology Department, Faculty of Medicine, Zagazig University, Egypt \\ Corresponding author: Heba A. Ahmed, email:heba_ahmed@zu.edu.eg \\ SMS: Saleh_Shafik@yahoo.com, MEMA: dr_hashem59@yahoo.com, STE: sanyaelghamry@yahoo.com, \\ AAA: doaa_ahmed57@yahoo.com \\ Received: 10-05-2014, Revised: 26-06-2014, Accepted: 03-07-2014, Published online: 12-08-2014
}

doi: 10.14202/vetworld.2014.594-600 How to cite this article: Ahmed HA, Shafik SM, Ali MEM, Elghamry ST and Ahmed AA (2014) Molecular detection of Toxoplasma gondii DNA in milk and risk factors analysis of seroprevalence in pregnant women at Sharkia, Egypt, Veterinary World 7(8):594-600.

\begin{abstract}
Aim: Toxoplasmosis is one of the most important zoonotic parasitic diseases worldwide. Infection is not only acquired by contact with the definitive host, but also by ingestion of raw milk and milk products. The aim of the study was to detect $T$. gondii DNA in milk samples, and to estimate anti-T. gondii antibodies in pregnant women for the analysis of the associated risk factors.

Materials and Methods: The study involved molecular examination of 150 milk samples collected from rural settings at Sharkia, Egypt. Seroprevalence of anti-T. gondii antibodies was determined in 100 pregnant women by indirect haemagglutination test. The analysis of risk factors associated with seropositive results was assessed by univariate and multivariate logistic regression.

Results:T. gondii DNA was detected in $8 \%$ and $2 \%$ of goat and sheep milk samples, respectively, while none of cow milk samples were positive. Seroprevalence of T. gondii antibodies in pregnant women was $82 \%$, anti-T. gondii-IgG and anti-T. gondii-IgM were detected in $63 \%$ and $11 \%$ serum samples, respectively. The results showed a significant correlation between the seroprevalence and the contact with cats and consumption of raw milk and homemade cheese.

Conclusion: The role of raw milk in transmission of $T$. gondii cannot be excluded. Contact with cats remains the main risk factor for acquiring $T$. gondii infection; also consumption of raw milk and milk products is considered an important risk factor. Further large scale studies are recommended to clarify the association of $T$. gondii seroprevalence with different risk factors.
\end{abstract}

Keywords: $B 1$ gene, pregnant women, raw milk, risk factors, seroprevalence, T. gondii.

\section{Introduction}

Toxoplasma gondii is a ubiquitous obligate intracellular blood protozoan which is widely distributed among warm-blooded animals and humans that are considered intermediate hosts [1,2]. All animals and birds consumed by humans can be considered a potential source of infection [1]. The public health significance of toxoplasmosis is not only due to direct contact with the definitive host (Family Felidae, such as domestic cats) but also due to consumption of infected meat and milk which can facilitate zoonotic transmission [3]. The medical and veterinary importance of toxoplasmosis is because the disease may cause abortion or congenital diseases in the intermediate hosts [4]. It has been estimated that up to one third of human population worldwide are infected with toxoplasmosis $[5,6]$. Human infection is usually subclinical; however, primary infection during pregnancy may cause spontaneous abortion or stillbirth. Moreover, the exposure of a newborn to the parasite in utero may develop congenital toxo-

Copyright: The authors. This article is an open access article licensed under the terms of the Creative Commons Attribution License (http://creativecommons.org/licenses/by/2.0) which permits unrestricted use, distribution and reproduction in any medium, provided the work is properly cited. plasmosis with major ocular and neurological complications $[5,6]$.

Different studies have reported that consumption of raw milk and milk products may play a role in the horizontal transmission of toxoplasmosis [7]. Contamination of milk with $T$. gondii could be originated from the infected animal or from contamination of milk with cats' feces since stray cats are commonly found around and within farms [3]. Several PCR assays have been developed for the detection of T. gondii DNA [8]. Such PCR reactions amplify different targets such as $\mathrm{B} 1$ gene, $\mathrm{P} 30$ or $18 \mathrm{~S}$ rDNA [9]. The $\mathrm{B} 1$ gene is a 35fold repetitive gene sequence with unknown function; PCR amplifying this target has shown high specificity for T. gondii DNA detection [9].

Seroprevalence of anti-Toxoplasma antibodies is so far the most frequently used test for the routine screening of toxoplasmosis in humans [10]. However, the results of sero-diagnosis are influenced by different factors such as geographic areas, the examined populations, cultural, hygienic and nutritional habits $[4,10,11]$.

Knowledge on the prevalence and risk factors of infection with T. gondii is essential for estimation of the burden of the disease and to design appropriate 
strategies for prevention of the disease. The aim of the current study was to examine raw milk of caprine, ovine and bovine sources collected from rural areas at Sharkia Province, Egypt, by amplification of $T$. gondii B1 gene. Moreover, the study aimed to estimate the seroprevalence of anti- $T$. gondii antibodies in serum samples collected from pregnant women at the same localities, to evaluate the associated risk factors.

\section{Materials and Methods}

Sampling: A cross-sectional study was conducted from December, 2013 to March, 2014, in rural areas at Sharkia Province, Egypt. A total of 150 milk samples from different milking animals (goats, sheep and cows, 50 each) were collected from small local outlets that buy the produced milk from in-house reared animals at the villages under investigation. Moreover, 100 venous blood samples without EDTA were collected from pregnant women presenting to antenatal clinic of the Obstetrics and Gynecology Department, Zagazig University Hospital, Sharkia, Egypt. The choice of the hospital for sample collection was based on its location in close proximity to the rural areas from which milk samples were collected. During sampling, a questionnaire was prepared to estimate the predisposing risk factors associated with seroprevalence.

\section{Molecular amplification of $\boldsymbol{B 1}$ gene:}

DNA extraction: From each examined animal, $50 \mathrm{ml}$ milk sample was collected and centrifuged at $2200 \mathrm{~g}$ for 5 minutes for concentration [12]. One $\mathrm{ml}$ of the sediment was re-suspended re-suspended in $200 \mu 1 \mathrm{TE}$ $(1 \mathrm{mM}$ EDTA, $10 \mathrm{mM}$ Tris- $\mathrm{HCl}(\mathrm{pH}=7.6))$ and $300 \mu \mathrm{l}$ $0.5 \mathrm{MEDTA}(\mathrm{pH}=8)$, and centrifuged at $3000 \mathrm{~g}$ for 10 minutes, to avoid interference by casein [13]. Milk pellet was then diluted in $200 \mu 1$ of PBS and DNA was extracted using the Thermo Scientific GeneJET Genomic DNA purification kit (Thermo Fisher Scientific, NYSE: TMO) according to the manufacturer guide.

PCR: Extracted DNA from milk was subjected to PCR for the amplification of the highly conserved 35-foldrepetitive B1gene [14]. The reaction was performed using the oligonucleotide primers TOXOB22 (Forward) 5'-AACGGGCGAGTAGC ACC TG AG GAGA-3' and TOXOB23 (Reverse) 5'-TGGGTC-TACGTCGATGG CATGACAAC-3' (synthesized by Biosearch Technologies Inc., USA) that amplify $115 \mathrm{bp}$ of the target. The reaction was performed in $20 \mu \mathrm{l}$ reaction volume containing $10 \mu 1$ of readymade $2 \mathrm{x}$ power DreamTaqGreen PCR mastermix (Thermo Fisher Scientific, NYSE: TMO), 20 pmol of B1 primers, each, and $2 \mu 1$ of the purified DNA. The reaction conditions consisted of one cycle of $95^{\circ} \mathrm{C}$ for $5 \mathrm{~min}$ followed by 40 cycles of $94^{\circ} \mathrm{C}$ for $30 \mathrm{sec}, 60{ }^{\circ} \mathrm{C}$ for $30 \mathrm{sec}$ and $72^{\circ} \mathrm{C}$ for $60 \mathrm{sec}$ and a final extension at $72^{\circ} \mathrm{C}$ for $10 \mathrm{~min}$. The reaction was carried out in Primus Thermal Cycler (MWGBiotech Thermal Cycler, Ebersberg, Germany). Amplification products were resolved in $1.2 \%(\mathrm{w} / \mathrm{v})$ agarose gels along with $100 \mathrm{bp}$ molecular weight ladder
(BioTeke Corporation, Shanghai, China). The agarose gel was prepared in $1 \mathrm{x}$ TBE ( 89 mMTris- Borate, 2 mM EDTA, and $\mathrm{pH}$ 8.3) stained with $5 \mu \mathrm{M}$ ethidium bromide. The gels were run in $1 \mathrm{xTBE}, 5 \mu \mathrm{M}$ ethidium bromide for at least 45 minutes at 100 volts and then visualized under ultraviolet light of a transilluminator (Spectroline, Westbury, NY, USA).A positive control $T$. gondii strain that was kindly obtained from Biotechnology Department, Animal health Research Institute, Dokki, Giza, and a reaction mixture with no added DNA were run in the PCR reaction as positive and negative controls, respectively.

Serology: Anti-T. gondii IgG and IgM antibodies were detected by indirect haemagglutination test using TOXOHAI FUMOUZE ${ }^{\circledR}$ kits (FUMOUZE DIAGNOSTICS, France) with a cutoff point of 1:80. Blood samples without anticoagulant were allowed to clot at room temperature for $15 \mathrm{~min}$, and then serum was collected for performing serology testing according to the manufacturer guidelines.

Risk factors analysis: A questionnaire included questions about the possible risk factors associated with $T$. gondii seroprevalence in pregnant women was filled individually for each participant during the study. The questionnaire included general information about the age, previous abortions and village of residence of the participants. Questions on the presence of cats, contact with soil (gardening or working in the field), rearing livestock and consumption of raw milk and homemade cheese were also included.

Statistical analysis: Bivariate and multivariate logistic regression models were fitted to determine factors associated with $T$. gondii infection using the computer program SPSS, Inc. version 22. Odds ratios (OR), COR: Crude Odd Ratio, AOR: Adjusted Odd Ratio and their $95 \%$ confidence interval $[95 \% \mathrm{CI}]$ were noted. Pvalues less than 0.05 were considered statistically significant.

\section{Results}

Molecular characterization of T. gondii DNA in milk samples by PCR: The presence of $T$. gondii DNA in milk was determined by amplification of $B 1$ gene using PCR reaction. The results in Table- 1 show that $8 \%$ of the examined goat milk samples were positive for $T$. gondii DNA, while $\%$ of sheep milk samples were positive (Figure-1). None of the examined cattle (cow) milk samples were positive for $T$. gondii DNA.

Serology: T. gondii antibodies were detected in $82 \%$ [82/100 (95\% CI: 73.1-89)] of the examined pregnant women serum samples by HAI test. Anti-T. gondii-IgG were detected in 63\% [63/100 (95\% CI: 52.8-72.4)], while anti-T. gondii-IgM were found in 11\% [11/100 (95\% CI: 5.6-18.8)] of the examined serum samples. Both IgG and IgM were detected in 8\% [8/100 (95\% CI: 3.5-15.2)] of the samples.

Risk factors associated with T. gondii seroprevalence: 


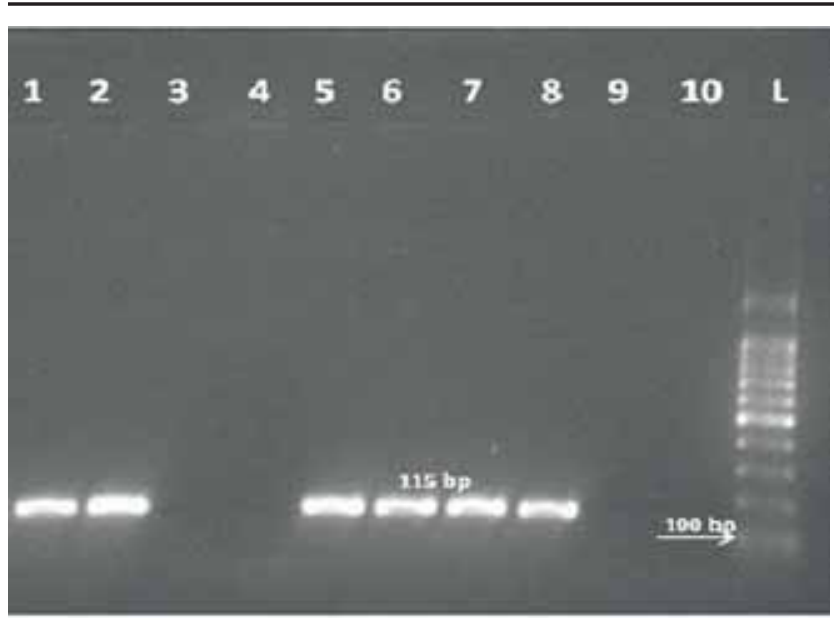

Table-1: Percent positivity of T. gondii DNA in animal milk samples as for detected by PCR.

\begin{tabular}{lcl}
\hline Source & Number examined & Number positive [\%(CI)] \\
\hline Goat milk & 50 & $4[8 \%(95 \%$ Cl: $2.2-19.2)]$ \\
Sheep milk & 50 & $1[2 \%(95 \%$ Cl: $0.1-10.6)]$ \\
Cattle milk & 50 & $0[0(95 \%$ Cl: $0-16.8)]$ \\
\hline
\end{tabular}

Figure-1: Agarose gel showing PCR results of $B 1$ gene amplification in the examined milk samples (L: 100 bp ladder, 1 : Positive control, 2: positive sheep milk sample, 3, 4, 9: negative samples, 5-8: positive goat milk samples, 10: Negative control).

Table-2: Factors associated with T. gondii seroprevalence in pregnant women

\begin{tabular}{|c|c|c|c|c|c|c|}
\hline \multirow[t]{2}{*}{ Characteristics } & \multicolumn{2}{|c|}{ Seroprevalence } & \multicolumn{2}{|c|}{ Bivariate } & \multicolumn{2}{|c|}{ Multivariate } \\
\hline & Positive n (\%) & Negative $n(\%)$ & $\operatorname{COR}(95 \% \mathrm{Cl})$ & Pvalue & AOR $(95 \% \mathrm{Cl})$ & Pvalue \\
\hline \multicolumn{7}{|l|}{ Age } \\
\hline $31-35$ & $40(85.1)$ & $7(14.9)$ & 1 & & 1 & \\
\hline $26-30$ & $22(81.5)$ & $5(18.5)$ & $0.95(0.31-2.99)$ & 0.935 & $0.73(0.13-4.19)$ & 0.722 \\
\hline $21-25$ & $20(76.9)$ & $6(23.1)$ & $0.65(.21-1.94)$ & 0.436 & $0.15(0.02-1.09)$ & 0.061 \\
\hline \multicolumn{7}{|l|}{ Previous abortion } \\
\hline Yes & $10(100)$ & 0 & $4.04 \mathrm{E}+08(0.0-)$. & 0.999 & $6.91 \mathrm{E}+08(0.0-)$. & 0.998 \\
\hline No & $72(80)$ & $18(20)$ & 1 & & 1 & \\
\hline \multicolumn{7}{|l|}{ Presence of cats } \\
\hline Yes & 69 (84.1) & $13(15.6)$ & $18.57(5.27-65.44)^{*}$ & $<0.000$ & 39.33(6.49-238.22) & $<0.000$ \\
\hline No & $4(22.2)$ & $14(77.8)$ & 1 & & 1 & \\
\hline \multicolumn{7}{|l|}{ Contact with soil } \\
\hline Yes & $60(87)$ & $9(13)$ & $2.73(0.96-7.76)$ & 0.060 & $2.46(0.62-9.83)$ & 0.202 \\
\hline No & $22(71)$ & 9 (29) & 1 & & 1 & \\
\hline \multicolumn{7}{|l|}{ Rearing goats } \\
\hline Yes & $62(79.5)$ & $16(20.5)$ & $.388(0.08-1.83)$ & 0.232 & $0.77(0.09-7.03)$ & 0.818 \\
\hline \multirow{2}{*}{\multicolumn{7}{|c|}{ Rearing sheep }} \\
\hline & & & & & & \\
\hline Yes & $23(82.1)$ & $5(17.9)$ & $1.01(0.33-3.16)$ & 0.982 & $0.55(0.10-3.02)$ & 0.495 \\
\hline No & $59(81.9)$ & $13(18.1)$ & 1 & & 1 & \\
\hline \multicolumn{7}{|l|}{ Rearing cattle } \\
\hline Yes & 47 (83.9) & $9(16.1)$ & $1.34(0.48-3.73)$ & 0.572 & $0.57(0.12-2.70)$ & 0.476 \\
\hline No & 35 (79.5) & $9(20.5)$ & 1 & & 1 & \\
\hline \multicolumn{7}{|c|}{ Consumption of raw milk and homemade cheese } \\
\hline Yes & $68(87.2)$ & $10(12.8)$ & $3.89(1.30-11.60)^{*}$ & 0.015 & $2.09(0.46-9.51)$ & 0.339 \\
\hline No & $14(63.6)$ & $8(36.4)$ & 1 & & 1 & \\
\hline
\end{tabular}

The number of pregnant women with IgMagainst T. gondii was too low to estimate the risk factors associated with acute infection separately, therefore, $\operatorname{IgM}$ and $\operatorname{IgG}$ positive results were compiled for the risk factors analysis. The age of pregnant women under investigation ranged from 21-35 years with a mean of 26.95 years (Table 2). There was insignificant increase of $T$. gondii seroprevalence pattern in association with age $(\mathrm{p}=0.7)$. A total of $10(10 \%)$ of the examined women had a history of previous abortion which had no significant effect on the seroprevalence of $T$. gondii antibodies $(\mathrm{p}=0.998)$.

The presence of domestic cats in $82(82 \%)$ of the studied households was recorded, of which, $69(84.1 \%)$ were seropositive (Table-2). The association of $T$. gondii seroprevalence with the presence of domestic cats in households was significant $(\mathrm{OR}=18.57,95 \%$ CI: 5.27-65.44, $\mathrm{p}<0.05)$. After multivariate analysis, there was also significant correlation between the presence of cats and $T$. gondii seroprevalence $(\mathrm{OR}=39.33,95 \%$ CI: 6.49-238.22, $\mathrm{p}<0.05)$. About $69 \%$ of the participants reported contact with soil during gardening or farming activities, of which, $87 \%$ were $T$. gondii seropositive (Table-2), however, there was no significant association with contact with soil and T. gondii seroprevalence $(\mathrm{p}=0.2)$.

Rearing goats, sheep and cattle were reported in $78 \%, 28 \%$ and $56 \%$ of the examined households, respectively, of which, the respective seroprevalence rates of $T$. gondii antibodies were $79.5 \%, 82.1 \%, 83.9 \%$. The association of rearing animals with $T$. gondii seroprevalence was insignificant (Table-2). Consumption of raw milk and homemade cheese was reported in $78 \%$ of the pregnant women under investigation, of which, $87.2 \%$ were seropositive (Table-2). The association of raw milk and homemade cheese consumption with $T$. gondii seroprevalence was significant $(\mathrm{OR}=3.89,95 \%$ CI: 1.3-11.6, $\mathrm{p}<0.05)$, however, after multivariate analysis, there was no significant association $(\mathrm{p}=0.3)$.

\section{Discussion}

Tachyzoites of $T$. gondii have been detected in 
milk of several intermediate hosts such as sheep, goats, cows and camels [4]. An experimental study verified the transmission of $T$. gondii to milk and offspring of female rat orally infected with the parasite [15]. In addition, breast milk of a mother with a history of acquiring toxoplasmosis due to consumption of raw sheep meat was reported to infect her infant after breast feeding [16]. Moreover, a study in Sudan has suggested that a high seropositivity for $T$. gondii $(67 \%)$ of pastoral nomads was correlated to the consumption of cameline raw milk [17].

Tachyzoites are easily destroyed by gastric enzymes; however, the role of ingestion in getting infection should not be ruled out [18]. Previous studies have reported that ingestion of tachyzoites in milk especially in infants resulted in $T$. gondii infection due to the low concentration of gastric enzymes [1]. Moreover, the survival of tachyzoites in acid pepsin solution for up to 2 hours may support the hypothesis of acquiring infection through consumption of milk and other food [18]. Another explanation to the possibility of acquiring infection by ingestion is that, in rare occasions, tachyzoites may penetrate the mucosal tissues, thus, they gain access to circulation before reaching the stomach $[1,19,20]$.

The results of the present study revealed that $T$. gondii DNA was detected in $8 \%$ of the examined goat milk samples (Table-1). Although the scarce data on prevalence of $T$. gondii in milk; the obtained results were nearly similar to a reported $10 \%$ prevalence of the parasite DNA in goat milk samples in Iran [21]. Moreover, $13 \%$ and $6.05 \%$ of $T$. gondii DNA detection in goat milk samples were also documented in Italy [22] and Brazil [23], respectively.

Different studies have documented the correlation between human infection with $T$. gondii and the consumption of unpasteurized goat milk $[19,20$, $24,25,26]$. In Brazil, human infection with T. gondii due to consumption of goat milk was reported and tachyzoites excretion was detected in milk of naturally infected goats [25].

The survival of $T$. gondii tachyzoites in milk was experimentally studied by Walsh et al. [27] who reported that the tachyzoites can survive in goat milk stored at $4{ }^{\circ} \mathrm{C}$ for 3-7 days. Furthermore, the infectivity of T.gondii cysts was maintained in bovine milk even after storage for 20 days at refrigerator temperatures [28]. The aforementioned studies support the hypothesis of the possible human infection due to consumption of raw milk and also the probability of tachyzoite shedding in milk.

Sheep milk samples were also examined for $T$. gondii DNA during the present study, $2 \%$ of the examined samples were positive by PCR (Table-1). Likewise, prevalence rates of $3.4 \%$ and $5 \%$ of $T$. gondii in sheep milk were also obtained in Italy [29] and Brazil [7], respectively.

Although none of the examined cow milk samples were positive for $T$. gondii DNA in the present study, the risk of acquiring infection due to consumption of bovine milk cannot be excluded. In accordance, Dubey [30] reported that the risk of acquiring toxoplasmosis by drinking cow's milk is minimal. A possible explanation of such condition could be that cattle seem to be able to reduce the number or even eliminate the parasite cysts from their tissues [31].

The obtained results put emphasis on the probability that any type of milk is a potential source of infection if consumed raw [1]. Therefore, pasteurization or boiling of milk is essential to prevent the public health hazard caused by $T$. gondii tachyzoites. Although the detection of $T$. gondii DNA in milk does not ensure the viability of the parasite in the milk sample [7], the detection of $T$. gondii DNA has an implication of the possible shedding of the parasite in milk. Therefore, the potential transmission of the parasite through consumption of raw milk cannot be underestimated.

Tests utilized for the detection of $\mathrm{IgG}$ and $\mathrm{IgM}$ antibodies in human blood are the most common for diagnosis of toxoplasmosis, however, these tests can not differentiate precisely between recent and previous infection [4]. The detection of Toxoplasma-specific IgM antibodies suggests an acute possible maternal infection during pregnancy and indicates the need for therapeutic intervention, whereas, IgG seroprevalence of $T$. gondii indicates past infection or acquired immunity $[32,33]$.

The present study showed an overall $82 \%$ seroprevalence of anti- $T$. gondii antibodies in the examined pregnant women serum samples. Similarly, in Nigeria, an overall $83.6 \%$ seroprevalence of anti- $T$. gondii antibodies among pregnant women was reported [33]. A study that was carried out in the same geographical area (Sharkia, Egypt) revealed that anti- $T$. gndii $\operatorname{IgG}$ and $\operatorname{IgM}$ seroprevalence in pregnant women were $30 \%$ and $10 \%$, respectively [34]. In Menoufia, Egypt, seroprevalence of Toxoplasma-specific IgG and IgM antibodies was determined by enzyme-linked fluorescent assay [32]. The results showed that $70.3 \%$ of the samples were seropositive, of which, seropositivity rates of $67.5 \%$ and $2.8 \%$ for IgG and IgM, respectively, were found [32]. Another study in Menoufia, Egypt, reported the seroprevalence of $27.3 \%$ of sera from pregnant women [35]. In Alexandria and Dakahlia, Egypt, studies have shown that IgG antibodies specific for T. gondii were reported in 46.2\% [36] and 51.5\% [37] of the examined pregnant women by ELISA, respectively. In Qualyobia, Egypt, ELISA results showed that $57.9 \%$ of pregnant women were seropositive for T. gondii antibodies, of which, $10.5 \%$ were positive for IgM [38]. Also, El-Gozamy et al. [39] reported 57.6\% seroprevalence among pregnant women in Qualyobia, Egypt. A possible explanation of the high seroprevalence in the present study ( $82 \%$ ) compared to the aforementioned studies could be the residence of all the participants in rural areas. Previous studies corroborate with this finding highlighting that the risk of acquiring $T$. gondii infection is significantly greater 
among pregnant women living in rural settings $[32,40$, 41]. The variation of $T$. gondii seroprevalence could be related to the use of different serological tests, geographic location, socioeconomic conditions, eating and hygienic habits [32].The seroprevalence of $\operatorname{IgG}$ in the examined samples during the present study $(63 \%)$ was nearly similar to $62.2 \%$ in Lebanon [42], $58.5 \%$ in Brazil [43] and 69.5\% in Turkey [44].

Different possible risk factors that could be associated with seroprevalence of anti-T. gondii antibodies were evaluated in pregnant women during the current study. The increase in the age of pregnant women has been reported to be associated with $T$. gondii infection $[11,33,43]$. Although insignificant, the increase in seropositivity to anti- $T$. gondii antibodies with the increase of age was observed in the present study (Table 2). Similar results were previously reported in Brazil [11] and Ethiopia [33] explaining such correlation to the increased frequency of exposure to infection sources with age. In relation to the history of abortion, there was insignificant association between previous abortions and seropositivity for toxoplasmosis (Table2). Likewise, a study in Brazil reported the same finding [43].

The obtained results revealed a significant association between T. gondii seroprevalence and the presence of domestic cats in houses (Table-2). This finding is in accordance with other results reported in Ethiopia [33, 45] and Brazil [43]. However, in contrast to the obtained results, El-Deeb et al.[32] found no significant correlation between seropositivity to antiT. gondii antibodies and contact with domestic cats in Menoufia, Egypt. This discrepancy could be attributed to the abundance of domestic stray cats in the study area rather than pet cats. Domestic stray cats are reported to be more exposed to the parasite than pet cats $[33,46]$. In Egypt, $T$. gondii infection of $97.4 \%$ feral cats was reported indicating the role of domestic cats in the dissemination of oocysts in the environment [32, 47].

Contact with soil (gardening or working in fields) has an insignificant effect on the seroprevalence of $T$. gondii in the participants of the current study (Table-2). This finding corroborates with other studies in USA [48], Ethiopia [33] and Brazil [11, 43]. However, the obtained findingwas inconsistent with El-Deeb et al.[32] who reported a correlation between contact with soil and $T$. gondii seroprevalence.

Significant association between the seroprevalence of $T$. gondii and contact with farm animals was reported previously in Egypt [32]. In contrast, the present study showed no significant correlation (Table-2).

Consumption of raw milk has been reported as an important source of acquiring T. gondii infection[7]. Similarly, El-Deeb et al.[32] in Menoufia, Egypt, reported significant correlation between raw milk consumption and T. gondii seroprevalence. In contrary, the current finding was inconsistent with other studies in USA [48], Ethiopia [45], Brazil [43] and Kyrgyz
Republic [49] that reported no significant correlation between raw milk consumption and $T$. gondii seroprevalence. This could be attributed to the type of consumed milk and the habit of using raw milk for the manufacture of homemade cheese in the current study.

Egyptian rural areas are known to have the habit of eating homemade cheese (Kareish) which is made from raw milk. Such habit has been shown to be pertinent acquisition of $T$. gondii and other microbial infection [32]. In addition, previous studies have shown that local homemade cheese from raw milk is considered a risk factor for public health [29]. This was supported by an experimental study conducted by Hiramoto et al. [28] who found that $T$. gondii cysts were able to survive the production process of homemade fresh cheese and storage for a period of 10 days at refrigeration temperature.

\section{Conclusion}

The present study reported the detection of $T$. gondii DNA in milk of goat and sheep in rural settings of Sharkia, Egypt. The study revealed also a high seroprevalence of $T$. gondii antibodies in pregnant women of the same rural residence. The asso-ciated risk factors have been presented, highlighting the significant correlation between the seroprevalence and the contact with cats and consumption of raw milk and homemade cheese. Data presented herein recommend the need for a further large scale study to clarify the association of $T$. gondii seroprevalence with different risk factors for more reliable conclusions. Also, screening for $T$. gondii infection during pregnancy should be considered to prevent and minimize congenital toxoplasmosis.

\section{Authors' contributions}

HAA, SMS, MEMA and STE: Designed the study and shared in the practical part on milk samples. HAA and AAA collected and examined human serum samples. HAA drafted and revised the manuscript. All authors read and approved the final manuscript

\section{Acknowledgements}

The authors are thankful to Mohamed Afifi for his valuable assistance in performing the statistical analysis. This study was funded by authors. Necessary facilities of University of Zagazig was used.

\section{Competing interests}

The authors declare that they have no competing interests.

\section{References}

1. Tenter, A. M. (2009) Toxoplasma gondii in animals used for human consumption. Mem. Inst. Oswaldo. Cruz., 104 (2): 364-369.

2. Weiss, L. M. and Dubey, J. P. (2009) Toxoplasmosis: A history of clinical observations. Int. J. Parasitol., 39 (8): 895-901.

3. Jittapalapong, S., Sangwaranond, A., Inpankaew, T., Phasuk, C., Pinyopanuwat, N., Chimnoi, W., Kengradomkij, C., Arunwipat, P. and Maruyama, S. (2008) Seroprevalence of Toxoplasma gondii infection in dairy cows in northeastern Thailand. Southeast Asian J. Trop. Med. Public Health, 39 
(suppl 1): 1-5.

4. Tenter, A. M., Heckeroth, A. R. and Weiss, L. M. (2000) Toxoplasma gondii: from animals to humans. Int. J. Parasitol., 30 (12-13): 1217-1258.

5. Havelaar, A. H., Kemmeren, J. M. and Kortbeek, L. M. (2007) Disease burden of congenital toxoplasmosis. Clin. Infect. Dis., 44 (11): 1467-1474.

6. Pappas, G., Roussos, N. and Falagas, M. E. (2009) Toxoplasmosis snapshots: global status of Toxoplasma gondii seroprevalence and implications for pregnancy and congenital toxoplasmosis. Int. J. Parasitol., 39 (12): 13851394.

7. Camossi, L. G., Greca-Junior, H., Correa, A. P., RichiniPereira, V. B., Silva, R. C., Da Silva, A. V. and Langoni, H. (2011) Detection of Toxoplasma gondii DNA in the milk of naturally infected ewes. Vet. Parasitol., 177 (3-4): 256-261.

8. Reischl, U., Bretagne, S., Kruger, D., Ernault, P. and Costa, J. M. (2003) Comparison of two DNA targets for the diagnosis of Toxoplasmosis by real-time PCR using fluorescence resonance energy transfer hybridization probes. BMC Infect. Dis., 3: 7.

9. Jones, C. D., Okhravi, N., Adamson, P., Tasker, S. and Lightman, S. (2000) Comparison of PCR detection methods for B1, P30, and 18S rDNA genes of $T$. gondii in aqueous humor. Invest. Ophthalmol. Vis. Sci., 41 (3): 634-644.

10. Jackson, M. H. and Hutchison, W. M. (1989) The prevalence and source of Toxoplasma infection in the environment. $A d v$. Parasitol., 28: 55-105.

11. Sroka, S., Bartelheimer, N., Winter, A., Heukelbach, J., Ariza, L., Ribeiro, H., Oliveira, F. A., Queiroz, A. J., Alencar, C., Jr. and Liesenfeld, O. (2010) Prevalence and risk factors of toxoplasmosis among pregnant women in Fortaleza, North-Eastern Brazil. Am. J. Trop. Med. Hyg., 83 (3): 528533.

12. Murphy, M. A., Shariflou, M. R. and Moran, C. (2002) High quality genomic DNA extraction from large milk samples. $J$. Dairy Res., 69 (4): 645-649.

13. Psifidi, A., Dovas, C. I. and Banos, G. (2010) A comparison of six methods for genomic DNA extraction suitable for PCR-based genotyping applications using ovine milk samples. Mol. Cell. Probes, 24 (2): 93-98.

14. Bretagne, S., Costa, J. M., Vidaud, M., Nhieu, J. T. V. and Feith, J. F. (1993) Detection of Toxoplasma gondii by competitive DNA amplification of bronchoalveolar lavage samples. J. Infect. Dis., 168 (6): 1585-1588.

15. Costa, V. M. and Langoni, H. (2010) Detection of Toxoplasma gondii in the milk of experimentally infected Wistar female rats. J. Venom Anim. Toxins incl. Trop. Dis., 16 (2): 368-374.

16. Bonametti, A. M., Passos, J. N., Koga da Silva, E. M. and Macedo, Z. S. (1997) Probable transmission of acute toxoplasmosis through breast feeding. J. Trop. Pediatr., 43 (2): 116 .

17. Elamin, E. A., Elias, S., Daugschies, A. and Rommel, M. (1992) Prevalence of Toxoplasma gondii antibodies in pastoral camels (Camelus dromedarius) in the Butana plains, mid-Eastern Sudan. Vet. Parasitol., 43 (3-4): 171-175.

18. Dubey, J. P. (1998) Re-examination of resistance of Toxoplasma gondii tachyzoites and bradyzoites to pepsin and trypsin digestion. Parasitol., 116 ( Pt 1) 43-50.

19. Riemann, H. P., Meyer, M. E., Theis, J. H., Kelso, G. and Behymer, D. E. (1975) Toxoplasmosis in an infant fed unpasteurized goat milk. J. Pediatr., 87 (4): 573-576.

20. Sacks, J. J., Roberto, R. R. and Brooks, N. F. (1982) Toxoplasmosis infection associated with raw goat's milk. JAMA, 248 (14): 1728-1732.

21. Dehkordi, F. S., Borujeni, M. R., Rahimi, E. and Abdizadeh, R. (2013) Detection of Toxoplasma gondii in raw caprine, ovine, buffalo, bovine, and camel milk using cell cultivation, cat bioassay, capture ELISA, and PCR methods in Iran. Foodborne Pathog. Dis., 10 (2): 120-125.

22. Mancianti, F., Nardoni, S., D'Ascenzi, C., Pedonese, F.,
Mugnaini, L., Franco, F. and Papini, R. (2013) Seroprevalence, detection of DNA in blood and milk, and genotyping of Toxoplasma gondii in a goat population in Italy. BioMed. Res. Int., 2013: 6.

23. Bezerra, M. J., Kim, P. C., Moraes, E. P., Sa, S. G., Albuquerque, P. P., Silva, J. G., Alves, B. H. and Mota, R. A. (2013) Detection of Toxoplasma gondii in the milk of naturally infected goats in the North-East of Brazil. Transbound Emerg. Dis. DOI: 10.1111/tbed.12160.

24. Chiari, C. A., Lima, W. S., Antunes, C. M. F. and Lima, J. D. (1987) Soroepidemiologia da toxoplasmose caprina em Minas Gerais. Brasil Arq. Bras. Med. Vet. Zootec., 39: 587609.

25. Chiari, C. A. and Neves, D. P. (1984) Toxoplasmose humana adquirida através da ingestão de leite de cabra. Memórias do Instituto. Oswaldo Cruz., 79: 337-340.

26. Skinner, L. J., Timperley, A. C., Wightman, D., Chatterton, J. M. and Ho-Yen, D. O. (1990) Simultaneous diagnosis of toxoplasmosis in goats and goatowner's family. Scand. $J$. Infect. Dis., 22 (3): 359-361.

27. Walsh, C. P., Hammond, S. E., Zajac, A. M. and Lindsay, D. S. (1999) Survival of Toxoplasma gondii tachyzoites in goat milk: potential source of human toxoplasmosis.J. Eukaryot. Microbiol., 46 (5): 73S-74S.

28. Hiramoto, R. M., Mayrbaurl-Borges, M., Galisteo, A. J., Jr., Meireles, L. R., Macre, M. S. and Andrade, H. F., Jr. (2001) Infectivity of cysts of the ME-49 Toxoplasma gondii strain in bovine milk and homemade cheese. Rev. Saude. Publica., 35 (2): 113-118.

29. Fusco, G., Rinaldi, L., Guarino, A., Proroga, Y. T., Pesce, A., Giuseppina, de M. and Cringoli, G. (2007) Toxoplasma gondii in sheep from the Campania region (Italy). Vet. Parasitol., 49(3-4): 271-274.

30. Dubey, J. P. (1991) Toxoplasmosis: an overview. South-East Asian J. Trop. Med. Public Health, 22 88-92.

31. Dubey, J. P. and Thulliez, P. (1993) Persistence of tissue cysts in edible tissues of cattle fed Toxoplasma gondii oocysts. Am. J. Vet. Res., 54 (2): 270-273.

32. El Deeb, H. K., Salah-Eldin, H., Khodeer, S. and Allah, A. A. (2012) Prevalence of Toxoplasma gondii infection in antenatal population in Menoufia governorate, Egypt. Acta Trop., 124(3): 185-191.

33. Zemene, E., Yewhalaw, D., Abera, S., Belay, T., Samuel, A. and Zeynudin, A. (2012) Seroprevalence of Toxoplasma gondii and associated risk factors among pregnant women in Jimma town, Southwestern Ethiopia. BMC Infect. Dis., 12 (1): 1-6.

34. Abd El-Ghany, A. M. and Merwad, A. M. A. (2012) Epidemiology and molecular detection of zoonotic Toxoplasma gondii in cat feces and seroprevalence of anti-Toxoplasma gondii antibodies in pregnant women and sheep. Life Sci. J., 9(1s): 133-146.

35. Azab, M. E., el-Shenawy, S. F., el-Hady, H. M. and Ahmad, M. M. (1993) Comparative study of three tests (indirect haemagglutination, direct agglutination, and indirect immuno-fluorescence) for detection of antibodies to Toxoplasma gondii in pregnant women. J. Egypt. Soc. Parasitol., 23 (2): 471-476.

36. Awadalla, H. N., El-Temsahy, M. M., Sharaki, O. A. and El Zawawy, L. A. (2008) Validity of IgG avidity enzyme linked immunosorbent assay and polymerase chain reaction for the determination of Toxoplasma infections during pregnancy. PUJ, 1:23-30.

37. Ibrahim, H. M., Huang, P., Salem, T. A., Talaat, R. M., Nasr, M. I., Xuan, X. and Nishikawa, Y. (2009) Short report: prevalence of Neospora caninum and Toxoplasma gondii antibodies in northern Egypt. Am. J. Trop. Med. Hyg., 80 (2): 263-267.

38. Hussein, A. H., Ali, A. E., Saleh, M. H., Nagaty, I. M. and Rezk, A. Y. (2001) Prevalence of Toxoplasma infection in Qualyobia governorate, Egypt. J. Egypt. Soc. Parasitol., 31 (2): 355-363. 
39. El-Gozamy, B. R., Mohamed, S. A. and Mansour, H. A. (2009) Toxoplasmosis among pregnant women in Qualyobia Governorate, Egypt. J. Egypt. Soc. Parasitol., 39 (2): 389-401.

40. Attia, R. A., el-Zayat, M. M., Rizk, H. and Motawea, S. (1995) Toxoplasma IgG. \& IgM. antibodies. A case control study.J. Egypt. Soc. Parasitol., 25 (3): 877-882.

41. Spalding, S. M., Amendoeira, M. R. R., Klein, C. H. and Ribeiro, L. C. (2005) Serological screening and toxoplasmosis exposure factors among pregnant women in South of Brazil. Rev. Soc. Bras. Med. Trop., 38 173-177.

42. Bouhamdan, S. F., Bitar, L. K., Saghir, H. J., Bayan, A. and Araj, G. F. (2010) Seroprevalence of Toxoplasma antibodies among individuals tested at hospitals and private laboratories in Beirut. Lebanese Med. J., 58: 8-11.

43. Moura, F. L. d., Amendoeira, M. R. R., Bastos, O. M. P., Mattos, D. P. B. G. d., Fonseca, A. B. M., Nicolau, J. L., Neves, L. B. d. and Millar, P. R. (2013) Prevalence and risk factors for Toxoplasma gondii infection among pregnant and postpartum women attended at public healthcare facilities in the City of Niterói, State of Rio de Janeiro, Brazil. Rev. Soc. Bras. Med. Trop., 46: 200-207.

44. Tekay, F. and Ozbek, E. (2007) The seroprevalence of Toxoplasma gondii in women from Sanliurfa, a province with a high raw meatball consumption. Turkiye Parazitol. Derg., 31 (3): 176-179.
45. Gebremedhin, E. Z., Abebe, A. H., Tessema, T. S., Tullu, K. D., Medhin, G., Vitale, M., Di Marco, V., Cox, E. and Dorny, P. (2013) Seroepidemiology of Toxoplasma gondii infection in women of child-bearing age in central Ethiopia. $B M C$ Infect. Dis., 13: 101.

46. Lee, S.E., Kim, J.Y., Kim, Y.A., Cho, S.H., Ahn, H.J., Woo, H.M., Lee, W.J. and Nam, H.W. (2010) Prevalence of Toxoplasma gondii infection in stray and household cats in regions of Seoul, Korea. Korean J. Parasitol., 48 (3): 267270.

47. Al-Kappany, Y. M., Rajendran, C., Ferreira, L. R., Kwok, O. C. H., Abu-Elwafa, S. A., Hilali, M. and Dubey, J. P. (2010) High prevalence of toxoplasmosis in cats from Egypt: isolation of viable Toxoplasma gondii, tissue distribution, and isolate designation. J. Parasitol., 96 (6): 1115-1118.

48. Jones, J. L., Dargelas, V., Roberts, J., Press, C., Remington, J. S. and Montoya, J. G. (2009) Risk factors for Toxoplasma gondii infection in the United States. Clin. Infect. Dis., 49 (6): 878-884.

49. Minbaeva, G., Schweiger, A., Bodosheva, A., Kuttubaev, O., Hehl, A. B., Tanner, I., Ziadinov, I., Torgerson, P. R. and Deplazes, P. (2013) Toxoplasma gondii infection in Kyrgyzstan: seroprevalence, risk factor analysis, and estimate of congenital and AIDS-related toxoplasmosis. PLoS Negl. Trop. Dis., 7 (2): e2043. 